\title{
ОБЛАСТІ ЗБЕРЕЖЕННЯ ЕНЕРГОВИТРАТ У ВАНТАЖНИХ МАНІПУЛЯТОРАХ НА ТРАНСПОРТНИХ ЗАСОБАХ
}

\begin{abstract}
АНОТАЦІЯ. Розглянуто особливості роботи маніпуляторів з шарнірно - зчленованою стрілою в областях виникнення розсіювання енергії. Для зменшення енерговитрат в системах, що розглядаються, пропонується визначення таких областей.

Ключові слова: маніпулятор, енерговитрати, збереження енергії.

АННОТАЦИЯ. Рассмотрены особенности работы манипуляторов с шарнирно-сочлененной стрелой в областях возникновения рассеяния энергии. Для уменьшения энергетических затрат в рассматриваемых системах, предлагается определение таких областей.

Ключевые слова: манипулятор, энергетические затраты, сохранение энергии.
\end{abstract}

SUMMARY. In the article the features work of manipulators are considered from joint - by an arthrous arrow in the areas of origin dispersion energy. With the purpose of reduction power expenses in such systems determination of such areas is offered for their subsequent research.

Key words: manipulator, power expenses, conservation of energy.

\section{Актуальність статті}

Транспортування і орієнтування маніпуляторами у просторі оброблюваних вантажів, що мають достатньо велику масу, висуває вимогу мінімізації енергетичних витрат. Витрати енергії маніпулятором залежать від виконуваної робочої операції та від програми іiі реалізації. Навіть за такої ж самої корисної роботи, яку виконує маніпулятор (наприклад, підйом вантажу на задану висоту), величина витрат енергії залежить від розташування початкових і кінцевих положень вантажу та траєкторії, за якої відбувається його перенесення [1]. Причиною таких відмінностей є дві особливості маніпуляторів: оброблювані вантажі є джерелом потенціальної енергії та наявність багатоланкового розімкненого кінематичного ланцюга.

Перша особливість виявляється у разі використання приводів, здатних розсіювати енергію, зокрема потенціальну. Друга особливість полягає в тому, що багатоланковий кінематичний ланцюг призводить до того, що при виконанні робочих операцій по транспортуванню вантажу в деяких приводах можливим $є$ розсіювання енергії навіть при загальній позитивній роботі, яку виконує маніпулятор.
Таким чином вивчення властивостей маніпуляторів розсіювати енергію дозволить знайти ділянки, на яких відбуваються подібні процеси, та визначити режими роботи 3 мінімізованими енерговитратами.

Метою дослідження $\epsilon$ встановлення умов розсіювання енергії у приводах шарнірно-зчленованої стріли вантажного крана-маніпулятора та визначення областей існування таких умов.

\section{Виклад основного матеріалу}

Розглянемо принципову схему маніпулятора із дросельним регулюванням (рис.1), що складається зі стояка 1 , плеча 2 , передпліччя 3, захватного пристрою (кисті) 4, привідних гідродвигунів 5, 6 та 7, гідророзподільника 83 електроприводом, насоса постійної продуктивності 9, дроселя змінного перерізу 10, фільтра 11.

Для запобігання перевантаження в гідросистемі маніпулятора встановлено два запобіжні клапани 12.

За допомогою гідроциліндрів 5 та 6 проводиться підйом або опускання вантажу 13. Гідроциліндром 7 відбувається орієнтація захвату 4 у площині зміни вильоту. 


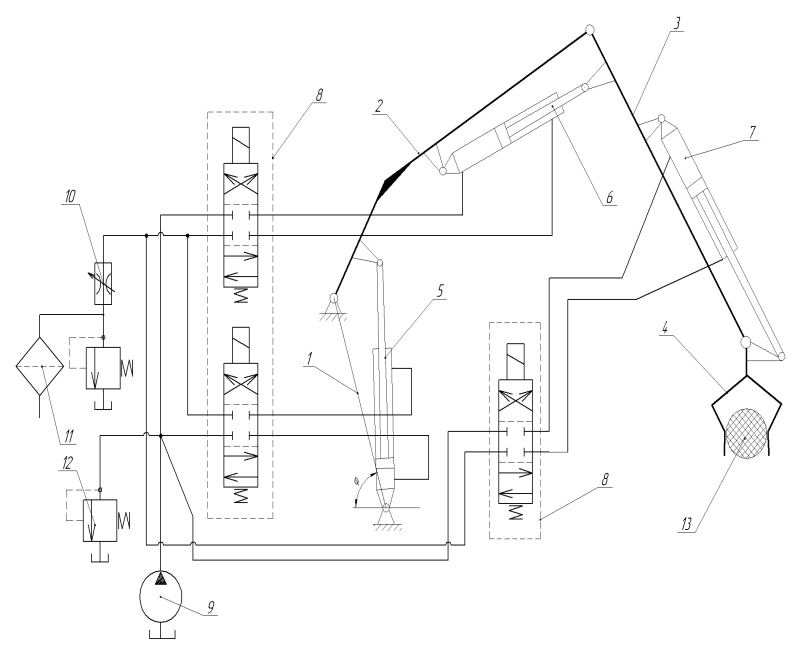

Рис. 1. Схема маніпулятора

На рис.1 видно, що коли відбувається опускання вантажу 13 , то його потенціальна енергія розсіюється у виконавчих гідроциліндрах, при цьому гідронасос 9 не перестає працювати і так само споживає енергію від механізму його приводу.

При переміщенні вантажу миттєва потужність приводів ланок маніпулятора витрачається на миттєву потужність корисних і шкідливих опорів, на миттєву потужність сил інерції і миттєву потужність сил ваги ланок маніпулятора. Рівняння передавання миттєвих потужностей для маніпулятора записується у вигляді

$$
\Sigma N_{i}=N_{n . c} \pm \Sigma N_{i н} \pm \Sigma N_{c . s}+\Sigma N_{m p},
$$

де $\Sigma N_{i}$ - миттєва потужність $i$-го приводу; $N_{n . c}-$ миттєва потужність, яка необхідна для переміщення вантажу в полі сили тяжіння; $\Sigma N_{i н}$ - миттєва потужність, що витрачається на подолання сил інерції; $\Sigma N_{c . s}$ - миттєва потужність, що витрачається на подолання сил ваги ланок маніпулятора; $\Sigma N_{m p}-$ миттєва потужність сил тертя у виконавчих механізмах.

Припустимо, що режим квазістатичний, тобто у будь-який момент часу виконуються умови статичної рівноваги, тоді можна записати

$$
\Sigma N_{i}=N_{n . c}=G \cdot v \cdot \cos \varphi,
$$

де $G$ - вага переміщуваного вантажу;

$v$ - швидкість переміщення вантажу; $\varphi-$ кут між напрямами сили ваги і швидкості.
Якщо кут $\varphi=90^{\circ}$ або $270^{\circ}$ (випадок горизонтального переміщення на рис.2), рівняння (2) матиме вигляд

$$
\Sigma N_{i}=0 .
$$

Звідси можна зробити висновок, що принаймні один із приводів працює в режимі, протилежному режиму решти приводів.

На рис.2 видно, що приводи плеча і кисті працюють у режимі від'ємної роботи або гальмівному режимі, тобто напрями кутових швидкостей в них співпадають 3 напрямом діючих моментів. Відповідно будемо мати:

$$
\left|N_{n n}\right|+\left|N_{\kappa}\right|-\left|N_{n p}\right|=0,
$$

де $\left|N_{n л}\right|,\left|N_{\kappa}\right|$ та $\left|N_{n p}\right|$ - відповідно миттєві потужності приводів плеча, кисті та передпліччя.

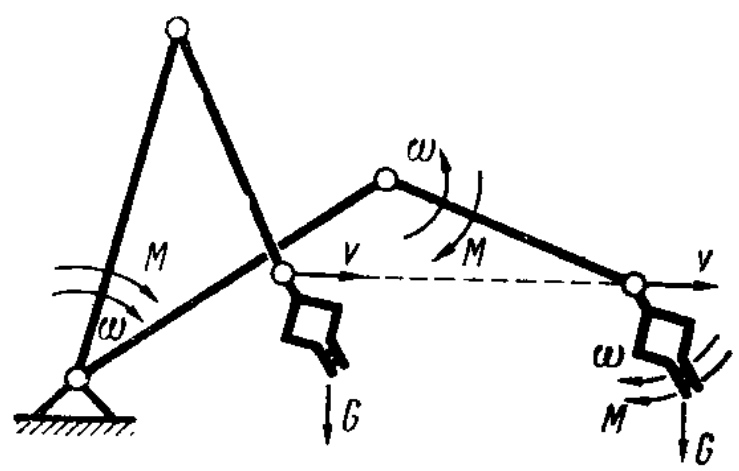

Рис. 2. Робота ланок маніпулятора при горизонтальному переміщенні вантажу

Якщо привід не має рекуперативних властивостей і в режимі негативної роботи споживає таку ж саму потужність, як і в руховому режимі, то в даному випадку загальна величина витрат потужності складе

$$
\Sigma N_{i}=2\left|N_{n p}\right| \text {. }
$$

При вертикальному підйомі вантажу для маніпулятора 3 двома шарнірно - зчленованими ланками, рівняння (1) прийме вигляд

$$
\Sigma N_{i}=G v .
$$

Тут також можна допустити, що один із приводів працює в гальмівному режимі [1]. Рівняння (2) для розглянутого випадку буде

$$
\left|N_{n n}\right|+\left|N_{n p}\right|=G v \text {. }
$$

Розглянемо схему маніпулятора (рис.3), що переміщує вантаж вагою $G$ із швидкіс- 
тю $v$ під кутом $\varphi$ до осі $X$. Припустимо, що центр ваги вантажу співпадає з центром захоплення $D$, причому при переміщенні вантажу забезпечується незмінне положення захвату щодо осі $X$, тобто швидкість точки $C$ дорівнює швидкості точки $D$, оскільки захват здійснює при цих допущеннях поступальний рух.

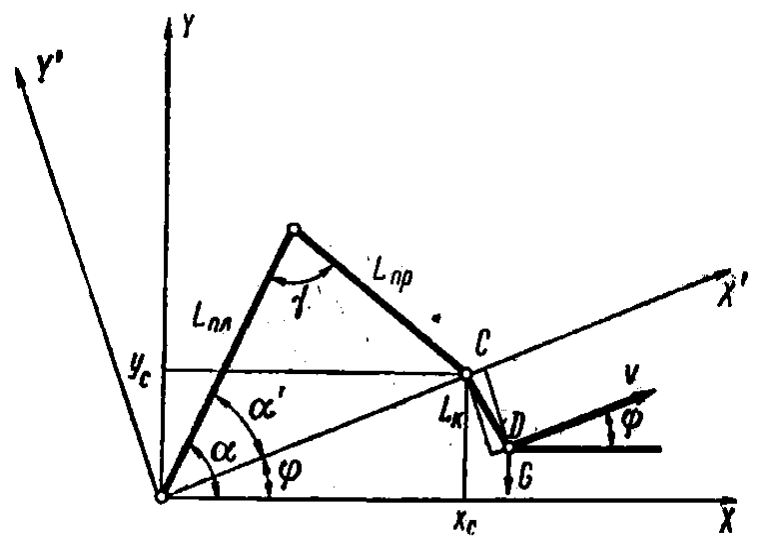

Рис. 3. Схема перенесення вантажу у площині

Нехай $X^{\prime} O Y^{\prime}$ - нова система координат, напрям осі $X^{\prime}$ якої співпадає із напрямом миттєвої швидкості $v$. Для визначення меж області розсіювання енергії у приводі плеча необхідно знайти множину точок, в якій миттєва потужність дорівнює нулю, тобто $M_{n l}=0$ i $\omega_{n l}=0$. У системі координат $X^{\prime} O Y^{\prime}$ кут між плечем і віссю $X^{\prime}$ дорівнює

$$
\alpha^{\prime}=\arccos \frac{L_{n s}^{2}-L_{n p}^{2}+\left(X_{c}^{\prime 2}+Y_{c}^{\prime 2}\right)}{2 L \sqrt{x+y}}+\operatorname{arctg} \frac{y_{c}^{\prime}}{x_{c}^{\prime}},
$$

де $x_{c}^{\prime}$ i $y_{c}^{\prime}-$ координати точки $C$. Диференціюючи за часом і враховуючи, що відбувається зміна тільки координати $x_{c}^{\prime}$, отримаєMO

$$
\begin{aligned}
& \omega_{n n}=\frac{d \alpha^{\prime}}{d t}=v \cdot\left(\frac{y_{c}^{\prime}}{x_{c}^{\prime 2}+y_{c}^{\prime 2}}+\frac{x_{c}^{\prime}\left(x_{c}^{\prime 2}+y_{c}^{\prime 2}-L_{n n}^{2}+L_{n p}^{2}\right)}{\left(x_{c}^{\prime 2}+y_{c}^{\prime 2}\right)} \times\right. \\
& \times \frac{1}{\sqrt{4 \cdot L_{n n}^{2} \cdot\left(x_{c}^{\prime 2}+y_{c}^{\prime 2}\right)-\left(L_{n n}^{2}-L_{n p}^{2}+x_{c}^{\prime 2}+y_{c}^{\prime 2}\right)}} .
\end{aligned}
$$

У системі координат ХOY маємо:

$$
\begin{aligned}
& \omega_{n n}=v \cdot\left(\frac{y_{c} \cos \varphi-x_{c} \sin \varphi}{x_{c}{ }^{2}+y_{c}{ }^{2}}+\frac{\left(x_{c}{ }^{2}+y_{c}{ }^{2}-L_{n n}^{2}+L_{n p}^{2}\right)}{\left(x_{c}{ }^{2}+y_{c}{ }^{2}\right)} \times\right. \\
& \left.\times \frac{\left(x_{c} \cos \varphi+y_{c} \sin \varphi\right)}{\sqrt{4 L_{n n}^{2}\left(x_{c}^{2}+y_{c}^{2}\right)-\left(L_{n n}^{2}-L_{n p}^{2}+x_{c}^{2}+y_{c}^{2}\right)^{2}}}\right)
\end{aligned}
$$

У разі вертикального підйому вантажу $\left(\varphi=90^{\circ}\right)$ рівняння (10) прийме вигляд:

$$
\begin{aligned}
& \omega_{n n}=v\left(-\frac{x_{c}}{x_{c}^{2}+y_{c}^{2}}+\frac{y_{c}\left(x_{c}^{2}+y_{c}{ }^{2}-L_{n n}^{2}+L_{n p}^{2}\right)}{\left(x_{c}^{2}+y_{c}^{2}\right)} \times\right. \\
& \left.\times \frac{1}{\sqrt{4 L_{n n}^{2}\left(x_{c}^{2}+y_{c}{ }^{2}\right)-\left(L_{n n}^{2}-L_{n p}^{2}+x_{c}{ }^{2}+y_{c}^{2}\right)^{2}}}\right) .
\end{aligned}
$$

При горизонтальному переміщенні вантажу ( $\varphi=0$ і $\varphi=180^{\circ}$ ) рівняння (10) буде

$$
\begin{aligned}
& \omega_{n \pi}= \pm v\left(-\frac{y_{c}}{x^{2}{ }_{c}+y^{2}{ }_{c}}+\frac{x_{c}\left(x_{c}{ }^{2}+y_{c}{ }^{2}-L_{n n}{ }_{n n}+L^{2}{ }_{n p}\right)}{\left(x_{c}{ }^{2}+y_{c}{ }^{2}\right)} \times\right. \\
& \left.\times \frac{1}{\sqrt{4 L_{n n}^{2}\left(x_{c}{ }^{2}+y_{c}{ }^{2}\right)-\left(L_{n n}^{2}-L_{n p}^{2}+x_{c}{ }^{2}+y_{c}{ }^{2}\right)^{2}}}\right),
\end{aligned}
$$

де знак плюс відповідає руху у додатному напрямі осі $X$, а знак мінус - від' $€$ мному.

Зрівнявши до нуля праву частину рівняння (11), визначимо межу області дисипації енергії у приводі плеча при вертикальному переміщенні вантажу:

$$
\frac{y_{c}\left(x_{c}^{2}+y_{c}^{2}-L_{n л}^{2}+L_{n p}^{2}\right)}{\sqrt{4 L_{n \lambda}^{2}\left(x_{c}^{2}+y_{c}^{2}\right)-\left(L_{n л}^{2}-L_{n p}^{2}+x_{c}^{2}+y_{c}^{2}\right)^{2}}}-x_{c}=0
$$

Після перетворення отримаємо:

$$
x_{c}{ }^{2}+y_{c}{ }^{2}-2 x_{c} L_{n p}-L_{n n}^{2}-L_{n p}^{2}=0,
$$

тобто межа області дисипації енергії у приводі плеча, знайдена щодо координат осі кистьового шарніра, є коло радіусом $R=L_{n p}$ i 3 координатами центру $x_{0}=L_{n p}$ i $y_{0}=0$.

Друга межа області дисипації енергії знаходиться за умови $M_{n л}=0$. Очевидно, що вона може бути визначена тільки для квазістатичного режиму і при вертикальному підйомі має вигляд $x_{0}=0$.

Із рівняння (12) видно, що за додатних значень $x_{c}$ і $y_{c}$ привід плеча при горизонтальному переміщенні вантажу, враховуючи постійність знака навантаження, працює тільки в одному із режимів негативної або позитивної роботи, залежно від напряму руху. При негативних значеннях $y_{c}$ можливі два режими роботи, які визначаються напрямом переміщення і поточними координатами. Прирівнявши нулю праву частину рівняння (12), отримаємо після ряду перетворень межу зміни режимів щодо координат точки $C$ 


$$
x_{c}^{2}+y_{c}^{2}+2 y_{c} L_{n p}-L_{n n}^{2}+L_{n p}^{2}=0,
$$

яка $\epsilon$ колом з радіусом $R=L_{n л}$ і координатами центру $x_{0}=0$ та $y_{0}=-L_{n p}$.

Визначимо межу області дисипації енергії у приводі передпліччя при вертикальному підйомі за умови $\omega_{n p}=0$. Кут $\gamma$ між плечем і передпліччям визначимо із співвідношення

$$
\gamma=\arccos \frac{L_{n n}^{2}+L^{2}{ }_{n p}-x^{2}{ }_{c}-y^{2}{ }_{c}}{2 L_{n n} L_{n p}} .
$$

Взявши похідну за часом цього рівняння отримаємо

$$
\omega_{n p}=\frac{d \gamma}{d t}=\frac{2 y_{c}}{\sqrt{4 L_{n l}^{2} L_{n p}^{2}-\left(L_{n l}^{2}+L_{n p}^{2}-x_{c}^{2}-y_{c}^{2}\right)^{2}}} .
$$

Зрівнявши до нуля значення кутової швидкості $\omega_{n p}$, отримаємо межу області дисипації енергії у приводі передпліччя у вигляді прямої лінії $y_{c}=0$.

Межами зміни режимів дисипації енергії у приводі плеча дволанкового маніпулятора при вертикальному підйомі вантажу є вісь $Y$ і коло з радіусом, що дорівнює довжині плеча, а центр кола лежить на вісі $X$ на відстані, рівній довжині передпліччя від початку координат. Межею зміни режимів у приводі передпліччя є вісь $X$ і коло з радіусом, що дорівнює довжині плеча, центр якої лежить на від'ємній вісі $Y$ на відстані, рівній довжині передпліччя від початку координат.

Області дисипації енергії у приводах плеча і передпліччя при вертикальному переміщенні вантажу зображено на рис.4 i побудовано для вертикального переміщення точки $C$, яка визначає положення вісі кистьового шарніра. Це викликано тим, що за поступального перенесення кисті їі положення щодо горизонтальної площини, не впливає на величину областей дисипації енергіï.

Заштриховані області $A$ відповідають режиму негативної роботи у приводі плеча, а заштриховані області $B$-режиму негативної роботи у приводі передпліччя. Обслуговувана зона, побудована за умови відсутності обмежень на розворот ланок, лежить між колами з радіусами $L_{n л}+L_{n p} \mathrm{i}\left|L_{n л}-L_{n p}\right|$. Iз рис.4 видно, що при зменшенні Lnp змен- шується теоретична обслуговувана зона при одночасному зменшенні областей дисипації енергії.
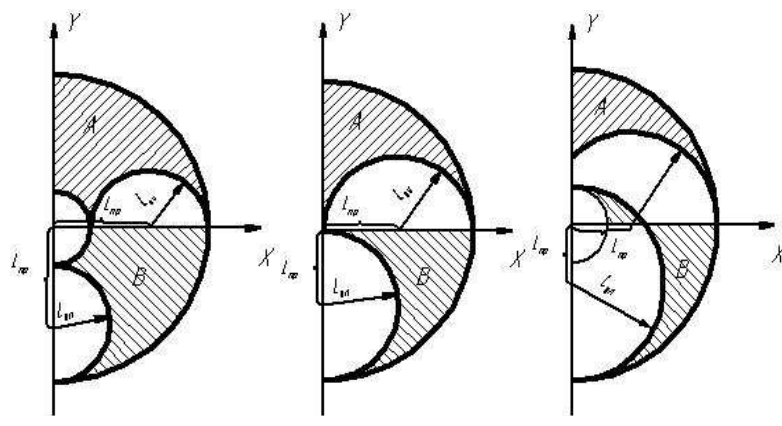

$L_{n l}<L_{n p}$ $L_{n л}=L_{n p}$

$L_{n л}>L_{n p}$

Рис.4. Області дисипації енергії у приводах ланок маніпулятора

Розгляд цих діаграм також показує, що при раціональному розміщенні реальної обслуговуваної зони у теоретичній обслуговуваній зоні, можна понизити ефект розсіювання енергії.

Вищеописані міркування дають можливість проаналізувати навантаження в ланках маніпулятора у визначених областях розсіювання енергії та визначити енергетичні затрати в гідроприводі маніпулятора. Визначення областей розсіювання енергії дає можливість спроектувати принципово нову систему гідроприводу вантажного крана - маніпулятора.

Так, для прикладу, розглянемо дві принципово нові системи гідроприводу.

Перша система гідроприводу маніпулятора складається із привідного гідроциліндра 1 , двопозиційного проточного двощілинного розподільника зі вмонтованим дроселем та електричним приводом 2 системи рекуперації енергії, керуючого електричного гідророзподільника 3 та гідравлічного насоса постійної продуктивності 4 (рис.5). Електронна система керування даного приводу складається із датчика руху ДР, що встановлений на гідроциліндрі 1 i визначає напрямок його руху, аналого цифрового перетворювача АЦП, цифро аналогового перетворювача ЦАП, підсилювача аналогового сигналу ПАС, портативного комп'ютера ПК, батареї живлення та з'єднувальних кабелів і шин. 


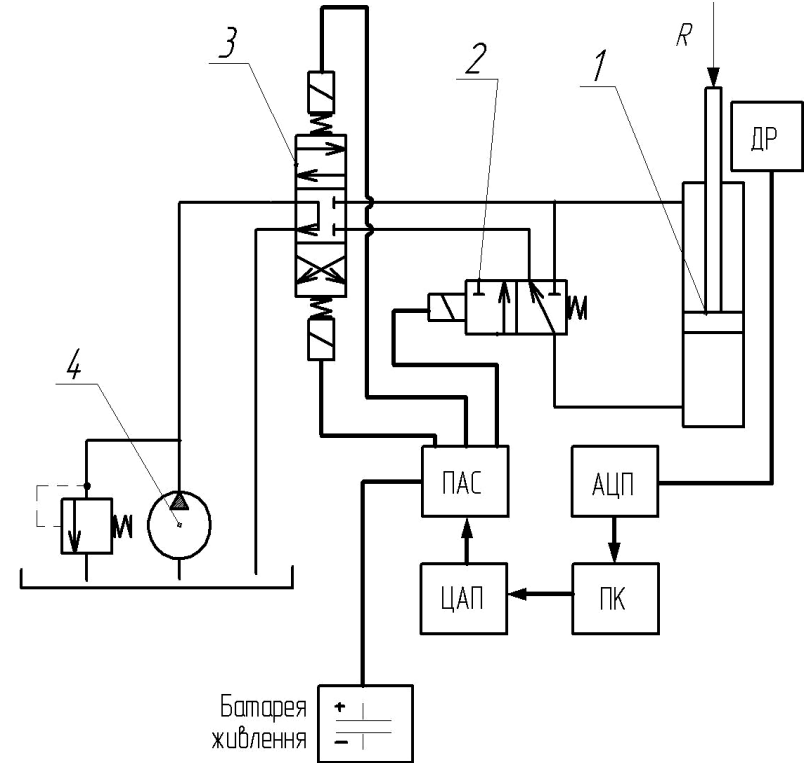

Рис. 5. Система гідроприводу із прямою рекуперацією енергії

Працює система таким чином (рис.5). При робочому ході з ПК подається сформований цифровий сигнал на ЦАП, де відбувається його перетворення в аналоговий сигнал і передавання через ПАС на торцеві електромагніти розподільника 3. Золотник розподільника 3 переміщується вгору у крайнє положення (при цьому золотник розподільника 2 залишається в заданому положення) і робоча рідина через робочі канали розподільника 3, трубопроводи та дросельний розподільник 2 потрапляє у поршневу порожнину циліндра 1 . Відбувається висування штока гідроциліндра 1 . У період, коли необхідне опускання штока гідроциліндра 1 , із ПК через ЦАП та ПАС на торцеві електромагніти подається сигнал, який переміщує золотник розподільника 3 вниз у крайнє положення, рідина 3 поршневої порожнини циліндра 1 починає зливатися в бак, а у штокову порожнину подаватиметься насосом 4 із бака. Як тільки шток почав втягуватися, датчик ДР фіксує його рух та подає сигнал через АЦП до ПК, де програма керування зчитує даний сигнал i формує новий, що подається через ЦАП і ПАС на розподільники 2 та 3 . Золотник розподільника 3 при цьому переміщується у нейтральне положення, а золотник розподільника 2 переміщується вправо, 3'єднавши поршневу та штокову порожнини гідроциліндра 1 .
За дії зовнішнього навантаження $R$ шток гідроциліндра буде втягуватися, перепускаючи при цьому рідину 3 поршневої порожнини у штокову. При цьому насос 4 задля економії енергії та моторесурсу може бути повністю відключений.

Друга система гідроприводу маніпулятора складається із привідного гідроциліндра 1 , керуючого електричного гідророзподільника 2, гідравлічного насоса постійної продуктивності 3 та системи рекуперації енергії, в яку входять двопозиційний проточний двощілинний розподільник зі вмонтованим дроселем та електричним приводом 4, двопозиційний однощілинний розподільник 5 , керуючий клапан 6 , гідроакумулятор 7 та система запірних клапанів 8 (рис.6). Електронна система керування аналогічна описаній вище.

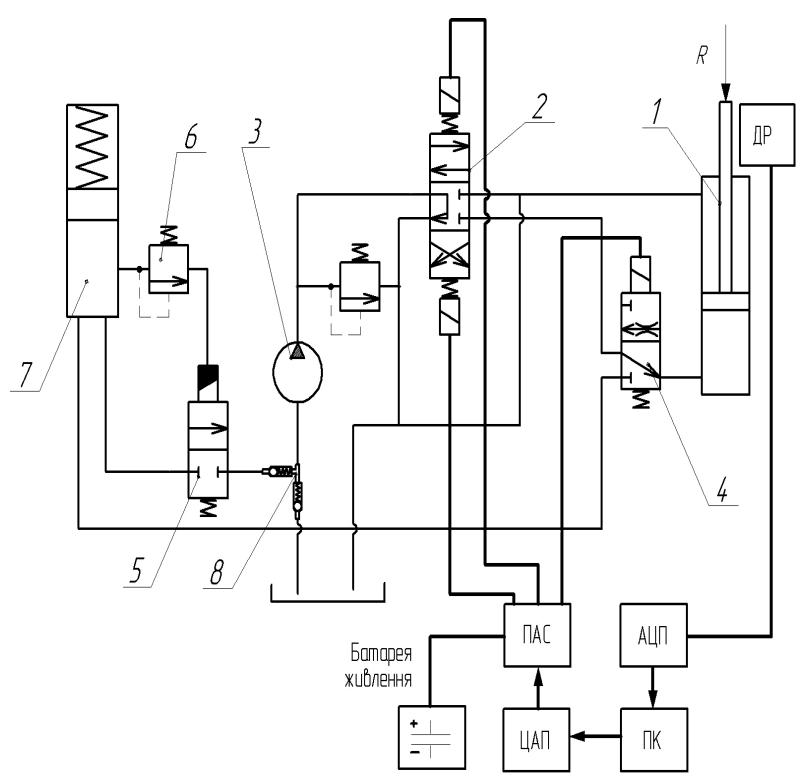

Рис. 6. Система гідроприводу із рекуперацією енергії від гідроакумулятора

Робота даного приводу схожа 3 попереднім, проте відрізняється тим, що в момент початку розсіювання енергії (при опусканні штока гідроциліндра під дією навантаження $R$ ), розподільник 4, при подачі керуючого сигналу з ПК, не замикає напряму поршневу та штокові порожнини гідроциліндра 1 (при цьому золотник розподільника 2 програмовано знаходиться у нейтральному положенні) і з'єднує поршневу лінію з гідроакумулятором 7 , а штокову - 3 гідро- 
баком. При цьому поршень гідроциліндра 1, при русі вниз, витіснятиме рідину з поршневої порожнини до гідроакумулятора 7 , а штокова порожнина всмоктуватиме рідину із бака. Гідроакумулятор відповідним чином збиратиме стиснену рідину у свою порожнину. Підтискна пружина гідроакумулятора забезпечить збереження отриманого тиску рідини.

При досягненні тиску в порожнині гідроакумулятора до значення, на яке налаштований клапан 6 , відкриється пропускний отвір золотника 5 і рідина під тиском через запірний клапан 8 потраплятиме у всмоктуючу лінію насоса 3 , що призведе до зменшення перепаду тиску на його торцях, а це зменшить навантаження на сам насос.

\section{Висновок}

У процесі роботи вантажного крана маніпулятора зі шарнірно-зчленованою стрілою, виникають області, в яких при виконанні загальної позитивної роботи деякі приводи працюють у гальмівному режимі, а величина споживаної ними миттєвої потужності перевищує величину корисної миттєвої потужності.

Межами областей розсіювання енергії у приводах ланок маніпулятора $\epsilon$ множина точок обслуговуючої зони, в якій миттєва потужність приводу при виконанні робочої операції дорівнює нулю. За заданої швидкості підйому вантажу та заданих розмірах ланок їхні кутові швидкості визначаються однозначно і відповідно межі зон розсіювання енергії, які отримані за умови $\omega=0$, постійні та не залежать від режиму роботи.

Гідроприводи вантажних кранів - маніпуляторів необхідно проектувати з рекуператорами енергії, які запропоновані в даній роботі для мінімізації розсіювання енергії.

\section{Література}

1. Бобринський А. Е., Степаненко Ю. А. Некоторые проблемы теории манипуляторов. В кн.: «Механика машин». М., «Наука». 1967, вып. 7 - 8, С. 4 - 23.

2. Черноусько Ф.Л., Болотник Н.Н., Градецкий В.Г. «Манипуляционные роботы: динамика, управление, оптимизация». - М.: Наука, 1989- 386 с.

3. К. Л. Навроиякий «Теория проектирования гидро- и пневмоприводов» М.: Машиностроение. 1988.

4. Лойчянский Л.Г., Лурьє А.И. «Курс теоретической механіки»: В 2-х т. T.II: Динамика. - М.: Наука. 1983. - 640с.

Рецензент: І.І.Назаренко, д.т.н. проф. (КНУБА)

Отримано: 13.05.2009 p. 